\title{
A Cross Sectional Study to Assess the Prevalence of Vitamin B 12 Deficiency Among Type 2 Diabetes Mellitus Patients on Metformin Therapy in A Tertiary Care Hospital in Eastern India.
}

\author{
Dr. Rimisomsengupta ${ }^{1}$,Dr. Purbanganguly ${ }^{2}$,Dr. Samir Chakraborty ${ }^{3,}$ \\ Dr. Upalsengupta ${ }^{4}$,Professor T.K.Mondol ${ }^{5}$ \\ ${ }^{I}$ Assistant Professor Department Of Internal Medicine PGIMSR \& ESIC Medical College, Joka \\ ${ }^{2}$ RMO-CUM-Clinical Tutor Paediatric Ophthalmology Division Regional Institute Of Ophthalmology \\ Medical College, Kolkata \\ ${ }^{3}$ Senior Resident Department Of Internal Medicine PGIMSR \& ESIC Medical College, Joka \\ ${ }^{4}$ Assistant Professor Department Of Nephrology KPC Medical College And Hospital \\ ${ }^{5}$ Head Of The Department Department Of Internal Medicine PGIMSR \& ESIC Medical College, Joka
}

\begin{abstract}
Introduction: Vitamin B12, a water soluble vitamin plays a pivotal role in DNA synthesis, Haemopoesis and maintenance of functional integrity of nervous system. A known pharmacological cause of Vitamin B12 deficiency is prolonged use of Metformin. This study intends to estimate and compare the Vitamin B12 levels among Type2 DM patients with or without Metformin.

Materials And Methods: A cross-sectional observational study of 227 patients divided into 121 patients on Metformin monotherapy and 106 patients on other oral hypoglycemic agents and Insulin monotherapy or combination therapy. Clinical examination and laboratory investigations including serum Vitamin B12 levels Was Conducted.

Result And Analysis: The Mean Vitamin B12 level among the Metformin Group was $523 \pm 231 \mathrm{pg} / \mathrm{ml}$ where as that in the Non-metformin group was $598 \pm 222 \mathrm{pg} / \mathrm{ml}$. The difference was statistically significant $(P=0.01$, $T=2.5)$. The serum Vitamin B12 levels showed a negative co-relation with daily dose of Vitamin B12 $(P=0.00)$. Conclusion: Long term use of Metformin predisposes to Vitamin B12 deficiency among Type 2 DM patients.A multi centre population based longitudinal analysis by future researchers is estimated to be further productive.

Keywords: Metformin, Vitamin B12, Type 2 DM
\end{abstract}

\section{Introduction}

Metformin is a biguanide class of oral hypoglycaemic agent ${ }^{1}$. It is one of the most frequently prescribed first line drugs in patients with Type 2 Diabetes Mellitus ${ }^{2-4}$. In cases where targeted glycemic control is not achieved, Metformin is widely combined with other oral hypoglycaemic agents like sulfonylurea and even with Insulin regimen ${ }^{5}$. Hepatic glucose output is decreased by Metformin in the fasting state ${ }^{6}$. Vitamin B12, a water soluble vitamin plays a pivotal role in DNA synthesis, Haemopoesis and maintenance of functional integrity of nervous system ${ }^{7}$. The classical clinical features of Vitamin B12 deficiency includes macrocytic RBCs with or without anemia, hypersegmented WBCs, pancytopenia, glossitis,mucositis, stomatitis and malabsorption, peripheral neuropathy,optic neuritis and sub acute combined degeneration of the spinal cord ${ }^{8}$. A known pharmacological cause of Vitamin B12 deficiency is prolonged use of Metformin. Metformin induced Viamin B12 deficiency is usually seen approximately 10-12 years of initiation of the drug. The condition is associated with decreased folate levels and increased Homocysteine and Methylmalonic Acid concentrations ${ }^{9}$. The exact mechanism for Metformin induced Vitamin B12 deficiency is not yet clear. The proposed mechanism is competitive inhibition of calcium dependent Vitamin B12-Intrinsic Factor complex at terminal ileum and bacterial overgrowth preventing Vitamin B12 absorption secondary to small bowel dysmotility ${ }^{10.11}$. It is estimated that $10-20 \%$ of patients on prolonged Metformin therapy will eventually develop Vitamin B12 deficiency ${ }^{12}$.

There is baseline line data for comparison of Vitamin B12 levels among Diabetic and non-diabetic population. In a country like India where due to diverse cultural belief a predominant section of the population is strictly vegetarian prevalence of Vitamin B12 deficiency is estimated to be high. Prevalence of Type 2 DM is also considerable in this part of the world ${ }^{13}$. Hence, estimation of Vitamin B12 levels among Type 2 DM patients on Prolonged Metformin therapy can guide in the comprehensive and effective management of Diabetes Mellitus. This study intends to estimate and compare the Vitamin B12 levels among Type2 DM patients. 


\section{Materials And Methods}

227 Type 2 DM patients within the age group of 30-70 years who had met the inclusion criteria were selected after stratified random sampling from the Diabetic Clinic OPD from December 2015 to November 2016. 121 patients were found to be on Metformin monotherapy with lifestyle modifications and 106 patients were found to be on other oral hypoglycaemic agents like sulfonylurea, DDPIV inhibitors( Sitagliptin and Vildagliptin), Insulin therapy or a combination of both. Patients with Metformin therapy atleast for 10 years were included only. Patients with Metformin and any other oral hypoglycaemic agents or insulin combination therapy were excluded. Patients with established micro or macrovascular complications especially peripheral neuropathy, patients with known history of chronic alcoholism, known haematological disorders, known history of GI Surgery, inflammatory bowel disease, prolonged(> 3 months) use of Proton pump inhibitors and strict Vegetarians were excluded from the study. Detailed history was elicited from all selected patients and comprehensive clinical examination was conducted. Laboratory estimation of fasting and post prandial blood sugar, HbA1C levels, Vitamin B 12 levels and complete hemogram was done. Vitamin B12 estimation was done by Cobas e 411 method.Vitamin B12 normal range was taken from $211 \mathrm{pg} / \mathrm{ml}$ to $946 \mathrm{pg} / \mathrm{ml}$.Collected data was systematically analysed using standard statistical methods.

\section{Result And Analysis}

The mean age group of both Metformin and non-Metformin groups were comparable (52.7 \pm 9.8 years versus $53.1 \pm 9.6$ years, $\mathrm{P}=0.7, \mathrm{~T}=0.3$ ). Both the study groups had a comparable gender distribution (Males $49.6 \%$ Versus $42.4 \%, \mathrm{P}=0.3$. Chi Square:0.9). The average duration of Diabetes among the Metformin group was $12.2 \pm 5.5$ yeras and that of the Non-metformin group was $16.1 \pm 6.1$ years. The difference was statistically significant $(\mathrm{P}<0.00, \mathrm{~T}=5.1)$. The mean $\mathrm{BMI}$ of the patients in both the groups were comparable $(\mathrm{P}=0.3, \mathrm{~T}=0.9)$. No statistically significant difference was elicited when the Fasting and Post Prandial blood sugar levels of the patients in both the groups were analysed $(\mathrm{P}=0.3, \mathrm{~T}=0.9 ; \mathrm{P}=0.3, \mathrm{~T}=1.1)$. The mean HbA1C levels among patients in both the groups were also comparable $(\mathrm{P}=0.06, \mathrm{~T}=1.1)$. There was no statistically significant difference among the two groups when prevalence of current smoking was analysed ( $\mathrm{P}=0.7$, Chi square:0.1) .

The proportion of hypertensive and dyslipidemic patients in both the groups were comparable ( $\mathrm{P}=0.9$, Chi Square:0.00). The average duration of Metformin use among patients in the Metformin Group was $11.9 \pm 1.1$ years and the mean daily dose of Metformin was $1226 \pm 450 \mathrm{mg}$. Among the Non-Metformin group $33.5 \%$ of the patients were on Insulin therapy where as $9.2 \%$ were on other oral Hypoglycemic drug monotherapy or combination therapy and the rest where on combination therapy of other oral hypoglycaemic drugs and Insulin. This distribution was highly skewed $(\mathrm{P}<0.00$, Chi Square: 142$)$.

The Mean Vitamin B12 level among the Metformin Group was $523 \pm 231 \mathrm{pg} / \mathrm{ml}$ where as that in the Non-metformin group was $598 \pm 222 \mathrm{pg} / \mathrm{ml}$. The difference was statistically significant $(\mathrm{P}=0.01, \mathrm{~T}=2.5)$. The mean haemoglobin concentration among the Metformin and Non-metformin group was $14.1 \pm 3.2$ and $14.0 \pm 2.9$ $\mathrm{gm} / \mathrm{dl}$ respectively and difference was not statistically significant $(\mathrm{P}=0.8, \mathrm{~T}=0.2)$. There was no clinical and laboratory evidence of Vitamin B12 deficiency anemia among patients in both the groups yet $9(7.4 \%)$ patients in the Metformin Group and 1(0.9\%) patient in the Non-metformin group was found to have Vitamin B12 levels below the lower normal range. This difference was statistically significant ( $\mathrm{P}=0.04$, Chi Square:4.2).

The mean Vitamin B12 level among patients taking daily $500 \mathrm{mg}$ of Metformin was $785 \pm 179 \mathrm{pg} / \mathrm{ml}$ where as among patients taking 500mg to $1000 \mathrm{mg}$ of daily Metformin, it was $543 \pm 147 \mathrm{pg} / \mathrm{ml}$. Among patients taking $1000 \mathrm{mg}$ to $2000 \mathrm{mg}$ of daily Metformin ,the mean Vitamin B12 level was $321 \pm 142 \mathrm{pg} / \mathrm{ml}$. On One way ANOVA test, the difference was highly statistically significant $(\mathrm{P}=0.00, \mathrm{~F}=48.62)$.

\section{Discussion}

The age and sex distribution of the Metformin group and the Non-metformin group in the present study are comparable. Similar findings have been echoed in the cross-sectional studies conducted separately by Kang $\mathrm{D}$ et $\mathrm{al}^{9}$ and Sato et $\mathrm{al}^{14}$. The mean duration of Diabetes was significantly different among the two groups in the present study implicating that patients requiring Insulin therapy had longer duration of Diabetes than patients on Metformin Monoptherapy. Almost similar findings have been documented by Kang et $\mathrm{al}^{9}$, where it has been shown that the patients with Metformin and Sulfonylurea combination had shorter duration of Diabetes than patients with Metformin and Insulin combination therapy. In the present study the average daily dose of Metformin was quite high(1226 $\pm 450 \mathrm{mg})$. Kang et $\mathrm{al}^{9}$ has shown that $1276.16 \pm 451.2 \mathrm{mg}$ mean daily Metformin dose among non-Insulin group and $1397.96 \pm 432.9 \mathrm{mg}$ among the Insulin group ( $\mathrm{P}=0.175)$. Equitable distribution of Metformin dosage among the two groups had negated any possible confounding factor in the study.The present study has also shown no statistically significant difference of glycemic control parameters among the two groups(p>0.05). Moreover, all patients with pre-existing risk factors for Vitamin B12 deficiency and patients with existing evidence of micro and macrovascular complications of Diabetes Mellitus have been excluded from the study. This has prompted a more unbiased estimation of any co-relation between prolonged 
Metformin use and Vitamin B12 concentration. However, in the study conducted by Kang et al ${ }^{9}$ there has been a statistically significant difference of $\mathrm{HbA1C}$ among the two groups $(\mathrm{P}<0.00)$. Kang et $\mathrm{al}^{9}$ had investigated that whether Metformin in combination with Sulfonylurea causes worse deterioration of Vitamin B12 levels as compared to combination Therapy with Insulin. The study has shown in clearer terms that mean serum Vitamin B12 levels among Metformin and sulfonylurea combination group was worse as compared to Metformin Insulin group $(\mathrm{P}<0.00)$. It was concluded that in patients with prolonged Metformin use Sulfonylurea is an independent risk factor for Vitamin B12 deficiency.

In the study conducted by Sato $\mathrm{Y}$ et $\mathrm{al}^{14}$, it was intended to find a co-relation between prolonged Metformin use and Viatmin B12 levels. Sato $\mathrm{Y}$ et $\mathrm{al}^{14}$ had shown beyond ambiguity that the mean Vitamin B12 level among Metformin treated group was significantly lower than that among non-Metformin group (250 \pm 89 $\mathrm{mg}, 318 \pm 140 \mathrm{mg}, \mathrm{P}=0.03)$. Similar findings have been echoed in the present study $((523 \pm 231 \mathrm{mg}$, $598 \pm 222 \mathrm{mg}, \mathrm{P}=0.01)$. However Sato et $\mathrm{al}^{14}$ has further shown that the Vitamin B12 levels among the Metformin group was comparable to that of the sub group of post gastrectomy people. Such sub group comparison was beyond the scope of the present study. The present study in agreement with the pioneering work conducted by Sato et $\mathrm{al}^{14}(\mathrm{P}=0.02$, spearman's $\rho=-0.3)$ has demonstrated a negative correlation of daily dose of Metformin with serum Vitamin B12 levels ( $\mathrm{P}=0.00)$. The authors of the present study feel unanimously that a longitudinal cohort analysis would have substantiated the present findings with better peer acceptance. The pioneering work done by Jager $\mathrm{J}$ De et $\mathrm{al}^{15}$ in Netherlands in a 4.3 years of longitudinal sub group analysis of the famous Hyperinsulinaemia: the Outcomeof its Metabolic Effects (HOME) randomised trial, has shown unambiguously that, compared with placebo, Metformin treatmentwas associated with a mean decrease in vitamin B12 concentration of $-19 \%(95 \%$ confidence interval $-24 \%$ to $-14 \%$; $\mathrm{P}<0.001)$ and in folate concentration of $-5 \%$ $(95 \% \mathrm{CI}-10 \%$ to $-0.4 \% ; \mathrm{P}=0.033)$, and an increase inhomocysteine concentration of $5 \%(95 \% \mathrm{CI}-1 \%$ to $11 \% ; \mathrm{P}=0.091)$.

\section{Conclusions}

The findings of this scientific work demonstrates beyond doubt that long term use of Metformin predisposes to Vitamin B12 deficiency among Type 2 DM patients. With increasing dose of daily Metformin consumption there is increased risk of getting comparatively lower blood levels of Vitamin B12. Undiagnosed Vitamin B12 deficiency might worsen the macro and microvascular complications of Diabetes Mellitus and this might significantly add to the Diabetes associated morbidity in the society. This being a cross-sectional study, have its inherrant limitations. Moreover, Folate and Homocysteine levels have not been investigated and compared concurrently and there was no blinding. Metformin being the cheapest and first line oral hypoglycaemic agent, is the lifeline of Diabetic treatment in this partof the world. A well defined guideline regarding the initiation and frequency of Vitamin B12 blood level monitoring among Diabetic patients on prolonged Metformin therapy is an urgent need of the day. The necessity of prophylactic Vitamin B12 supplementation also needs to be investigated and scrutinised. The present study has tried to throw some light in this direction. A multi centre population based longitudinal analysis by future researchers is estimated to be further productive.

[1]. Bouchoucha M, Uzzan B, Cohen R. Metformin and digestive disorders.Diabetes Metab.2011; 37: 90-6.

[2]. American Diabetes Association. Standards of medical care in diabetes-2014. Diabetes Care 37 Suppl. 2014; 1: S14-80.

[3]. Nathan DM, Buse JB, Davidson MB, Ferrannini E, Holman RR, et al.Medical management of hyperglycemia in type 2 diabetes: a consensus algorithm for the initiation and adjustment of therapy: a consensus statement of the American Diabetes Association and the European Association for the Study of Diabetes. Diabetes Care.2009; 32: 193-203.

[4]. Ko SH, Kim SR, Kim DJ, Oh SJ, Lee HJ, et al.Clinical practice guidelines for type 2 diabetes in Korea. Committee of ClinicalPractice Guidelines, Korean Diabetes Association. Diabetes Metab J.2011; 35:431-436.

[5]. Turner LW, Nartey D, Stafford RS, Singh S, Alexander GC. Ambulatory treatment of type 2 diabetes in the U.S., 1997-2012. Diabetes Care.2014; 37: 985-92.

[6]. Kumthekar AA, Gidwani HV, Kumthekar AB. Metformin associated B12 deficiency.JAPI.2012;60:58-9.

[7]. Oh R, Brown D: Vitamin B12 Deficiency. Am Fam Physician. 2003; 67:979-86

[8]. Aslinia F, Mazza J, Yale S: MegaloblasticAnemia and Other Causes of Macrocytosis. Clinical Medicine \& Research. 2006; 4:23641.

[9]. Kang D, Yun J, Ko S et al. Higher Prevalence of Metformin-Induced Vitamin B12 Deficiency in Sulfonylurea Combination Compared with Insulin Combination in Patients with Type 2 Diabetes: A Cross-Sectional Study. PLOS ONE. 2014;9(10):1-8.

[10]. Andre`s E, Noel E, Goichot B: Metformin-associated vitamin B12 deficiency. Arch Intern Med 2002; 162:2251-2.

[11]. Bauman W, Shaw S, Jayatilleke E, Spungen A, Herbert V. Increased intake of calcium reverses vitamin B12 malabsorption induced by metformin. Diabetes Care. 2000;23:1227-31.

[12]. Tomkin GH, Hadden DR, Weaver JA, Montgomery DA. Vitamin- B12 status of patients on long-term metformin therapy. BMJ.1971;2:685- 7 .

[13]. Kibirige D, Mwebaze R: Vitamin B12 deficiency among patients with diabetes mellitus: is routine screening and supplementation justified? Journal of Diabetes \& Metabolic Disorders. 2013;12:17.

[14]. Sato Y, Ouchi K, Funase Y et al. Relationship between metformin use, vitamin B12 deficiency, hyperhomocysteinemia and vascular complications in patients with type 2 diabetes.Endocrine Journal. 2013; 60(12):1275-80. 
[15]. Jager J De, Kooy A, Lehert P et al. Long term treatment with metformin in patients with type 2 diabetes and risk of vitamin B-12 deficiency: randomised placebo controlled trial. BMJ.2010; 340:1-7.

Figures and Charts

Table 1: Showing the distribution of the study subjects according to clinical and other parameters among the two groups $(\mathrm{N}=227)$ :

\begin{tabular}{|c|c|c|c|c|}
\hline Parameters & $\begin{array}{l}\text { Metformin } \\
\text { (n1=121) }\end{array}$ & Group & $\begin{array}{l}\text { Non-Metformin Group } \\
(\mathrm{n} 2=106)\end{array}$ & P value \\
\hline Mean Age & $52.7 \pm 9.8$ & & $53.1 \pm 9.6$ & $\begin{array}{l}\mathrm{P}=0.7 \\
\mathrm{~T}=0.3\end{array}$ \\
\hline $\operatorname{Men}(\%)$ & $60(49.6 \%)$ & & $45(42.4 \%)$ & $\begin{array}{l}\mathrm{P}=0.3 \\
\text { Chi sq: } 0.9\end{array}$ \\
\hline $\begin{array}{l}\text { Duration Of Diabetes } \\
\text { (in years) }\end{array}$ & $12.2 \pm 5.5$ & & $16.1 \pm 6.1$ & $\begin{array}{l}\mathrm{P}<0.00 \\
\mathrm{~T}=5.1\end{array}$ \\
\hline Mean BMI(Kg/m2) & $24.3 \pm 3.1$ & & $24.7 \pm 3.2$ & $\begin{array}{l}\mathrm{P}=0.3 \\
\mathrm{~T}=0.9\end{array}$ \\
\hline Smoking(\%) & $12(9.9 \%)$ & & $8(7.5 \%)$ & $\begin{array}{l}\mathrm{P}=0.7 \\
\text { Chi Sq:0.1 }\end{array}$ \\
\hline Hypertension(\%) & $54(44.6 \%)$ & & $46(43.4 \%)$ & $\begin{array}{l}\mathrm{P}=0.9 \\
\text { Chi Sq:0.0 }\end{array}$ \\
\hline Mean FBS(Mg/dl) & $123 \pm 23$ & & $126 \pm 26$ & $\begin{array}{l}\mathrm{P}=0.3 \\
\mathrm{~T}=0.9\end{array}$ \\
\hline Mean PPBS(Mg/dl) & $154 \pm 32$ & & $159 \pm 38$ & $\begin{array}{l}\mathrm{P}=0.3 \\
\mathrm{~T}=1.1\end{array}$ \\
\hline
\end{tabular}


A Cross Sectional Study To Assess The Prevalence Of Vitamin B 12 Deficiency Among ..

\begin{tabular}{|c|c|c|c|}
\hline Mean HbA1C & $7.2 \pm 1.4$ & $7.6 \pm 1.8$ & $\begin{array}{l}\mathrm{P}=0.06 \\
\mathrm{~T}=1.9\end{array}$ \\
\hline Dyslipidemis(\%) & $23(19 \%)$ & $19(17.9 \%)$ & $\begin{array}{l}\mathrm{P}=0.9 \\
\text { Chi Sq:0.0 }\end{array}$ \\
\hline $\begin{array}{lll}\text { Mean } \quad \text { Duration } & \text { of } \\
\text { Metformin use(in Years) } & \end{array}$ & $11.9 \pm 1.1$ & Not Applicable & $\begin{array}{l}\text { Not } \\
\text { Applicable }\end{array}$ \\
\hline $\begin{array}{l}\text { Mean Daily Dose of } \\
\text { Metformin }\end{array}$ & $1226 \pm 450$ & Not Applicable & $\begin{array}{l}\text { Not } \\
\text { Applicable }\end{array}$ \\
\hline $\begin{array}{l}\text { Mean Vitamin B12 levels } \\
(\mathrm{pg} / \mathrm{ml})\end{array}$ & $523 \pm 231$ & $598 \pm 222$ & $\begin{array}{l}\mathrm{P}=0.01 \\
\mathrm{~T}=2.5\end{array}$ \\
\hline $\begin{array}{l}\text { Laboratory evidence of } \\
\text { Vitamin B12 deficiency }(\%)\end{array}$ & $9(7.4 \%)$ & $1(0.9 \%)$ & $\begin{array}{l}\mathrm{P}=0.04 \\
\text { Chi Sq:4.2 }\end{array}$ \\
\hline $\begin{array}{ll}\text { Mean } & \text { Hemoglobin } \\
\text { Concentration } & \\
\end{array}$ & $14.1 \pm 3.2$ & $14.0 \pm 2.9$ & $\begin{array}{l}\mathrm{P}=0.8 \\
\mathrm{~T}=0.2\end{array}$ \\
\hline
\end{tabular}

Table 2: Showing the Correlation of mean Vitamin B12 levels with Metformin Drug dosage (n1=121)

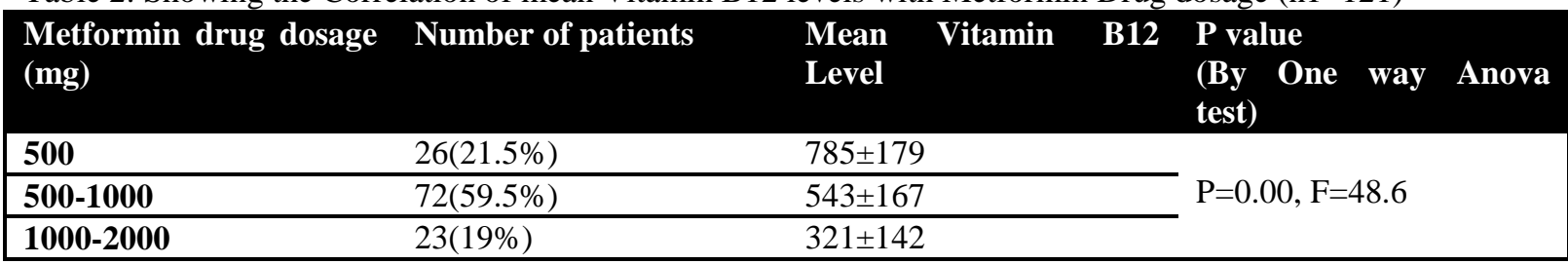

Figure1: Showing the distribution of the study population according to the nature of Hypoglycemic Medication ( $\mathrm{N}=227$ )

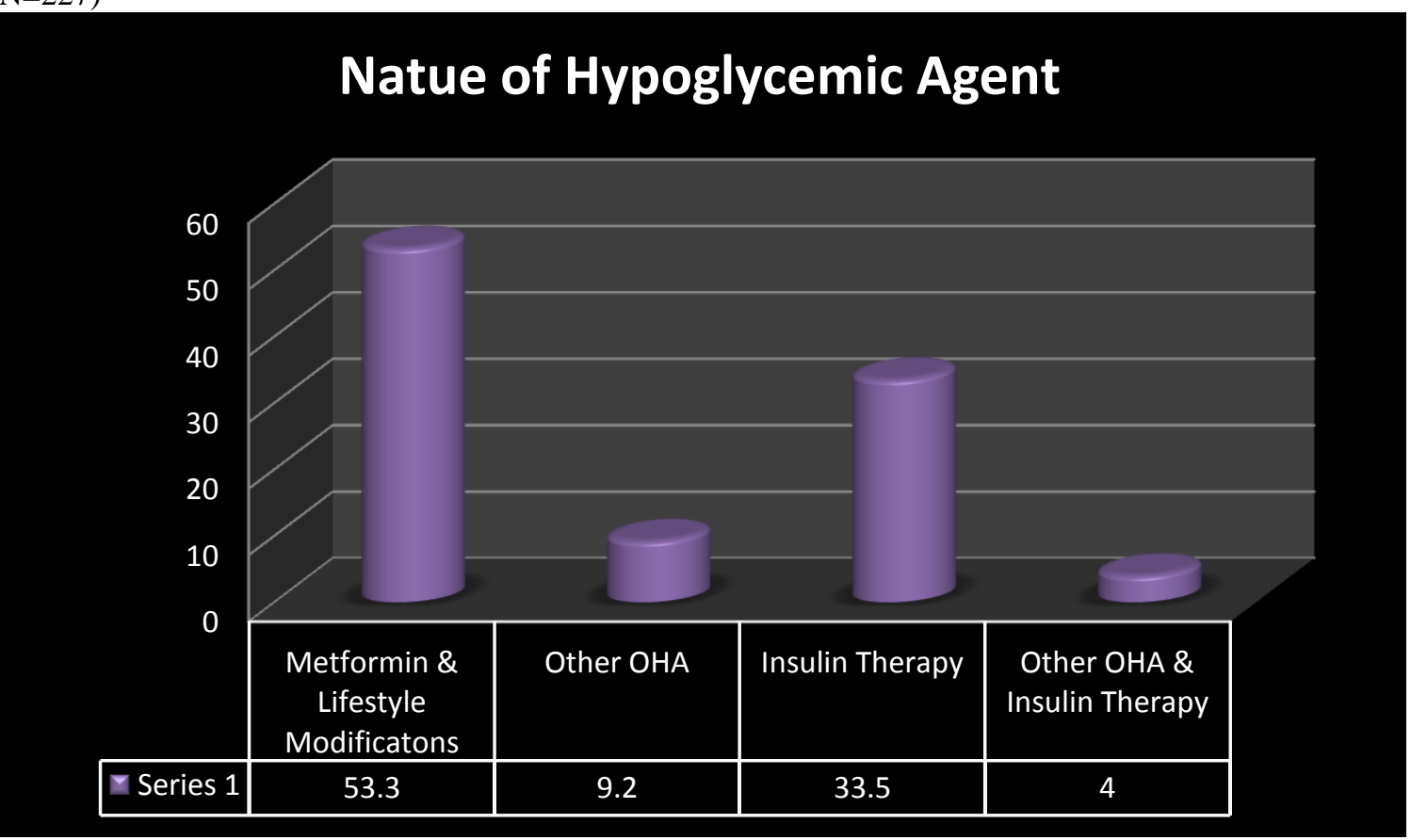

